\title{
Pregnant Women Hospitalized with Chikungunya Virus Infection, Colombia, 2015
}

\author{
Maria Escobar, Albaro J. Nieto, Sara Loaiza-Osorio, Juan S. Barona, Fernando Rosso
}

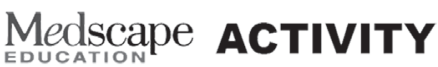

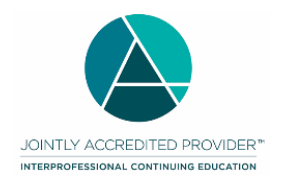

In support of improving patient care, this activity has been planned and implemented by Medscape, LLC and Emerging Infectious Diseases. Medscape, LLC is jointly accredited by the Accreditation Council for Continuing Medical Education (ACCME), the Accreditation Council for Pharmacy Education (ACPE), and the American Nurses Credentialing Center (ANCC), to provide continuing education for the healthcare team.

Medscape, LLC designates this Journal-based CME activity for a maximum of 1.00 AMA PRA Category 1 Credit(s) ${ }^{\mathrm{TM}}$. Physicians should claim only the credit commensurate with the extent of their participation in the activity.

All other clinicians completing this activity will be issued a certificate of participation. To participate in this journal CME activity: (1) review the learning objectives and author disclosures; (2) study the education content; (3) take the post-test with a $75 \%$ minimum passing score and complete the evaluation at http://www.medscape.org/journal/eid; and (4) view/print certificate. For CME questions, see page 1940.

Release date: October 13, 2017; Expiration date: October 13, 2018

Learning Objectives

Upon completion of this activity, participants will be able to:

- $\quad$ Assess clinical findings associated with chikungunya virus (CHIKV) infection during pregnancy

- Distinguish the common laboratory abnormality associated with CHIKV infection during pregnancy

- $\quad$ Evaluate clinical outcomes associated with CHIKV infection during pregnancy

- Analyze symptoms of CHIKV infection after pregnancy

\section{CME Editor}

Kristina B. Clark, PhD, Copyeditor, Emerging Infectious Diseases. Disclosure: Kristina B. Clark, PhD, has disclosed the following relevant financial relationships: owns stock, stock options, or bonds from cooper Companies, Inc.; McKesson Corp; Medtronic; STERIS; Bio-Techne Corp.

\section{CME Author}

Charles P. Vega, MD, Health Sciences Clinical Professor, UC Irvine Department of Family Medicine; Associate Dean for Diversity and Inclusion, UC Irvine School of Medicine, Irvine, California, USA. Disclosure: Charles P. Vega, MD, has disclosed the following financial relationships: served as an advisor or consultant for McNeil Consumer Healthcare; served as a speaker or a member of a speakers bureau for Shire Pharmaceuticals.

\section{Authors}

Disclosures: Maria Fernanda Escobar Vidarte, MD, MSc; Albaro José Nieto Calvache, MD; Sara del Pilar Loaiza Osorio, MD; Juan Sebastian Barona Wiedmann, MD; and Fernando Rosso Suarez, MD, MSc, have disclosed no relevant financial relationships.

In 2015 in Colombia, 60 pregnant women were hospitalized with chikungunya virus infections confirmed by reverse transcription PCR. Nine of these women required admission to the intensive care unit because of sepsis with hypoperfusion and organ dysfunction; these women met the criteria for severe acute maternal morbidity. No deaths occurred. Fifteen women delivered during acute infection;

Author affiliations: Fundación Clínica Valle del Lili, Cali, Colombia (M. Escobar, A.J. Nieto, S. Loaiza-Osorio, F. Rosso); Icesi University, Cali (M. Escobar, A.J. Nieto, J.S. Barona, F. Rosso)

DOI: https://doi.org/10.3201/eid2311.170480 some received tocolytics to delay delivery until after the febrile episode and prevent possible vertical transmission. As recommended by a pediatric neonatologist, 12 neonates were hospitalized to rule out vertical transmission; no clinical findings suggestive of neonatal chikungunya virus infection were observed. With 36 women $(60 \%)$, follow-up was performed 1 year after acute viremia; 13 patients had arthralgia in $\geq 2$ joints (a relapse of infection). Despite disease severity, pregnant women with chikungunya should be treated in high-complexity obstetric units to rule out adverse outcomes. These women should also be followed up to treat potential relapses. 
$\mathrm{C}$ hikungunya virus (CHIKV) is an alphavirus of the family Togaviridae that was isolated for the first time in Tanganyika (now Tanzania) in 1952 (1). CHIKV is transmitted to humans by several species of mosquito; Aedes aegypti and Ae. albopictus are the main vectors. Since 2004, the geographic distribution of the virus has expanded, which has led to major epidemics in Asia and Africa (2).CHIKV appeared as an emerging infection in the Americas in late 2013, with $\approx 1.1$ million reported cases (3). In Colombia, by the 51st week of 2016, a total of 19,525 cases of CHIKV had been reported; 19,091 (97.8\%) had symptoms suggestive of chikungunya, but only $206(1.1 \%)$ had been confirmed positive for the virus by laboratory tests (4). Acute infection with CHIKV is characterized by high fever, asthenia, headache, emesis, rash, myalgia, and arthralgia $(1,5)$. Infected persons usually recover spontaneously within several days or a week (6), but arthralgia can persist for months or even years (7).

Knowledge about CHIKV infection has been derived mostly from a large outbreak that occurred in Réunion Island in 2005. Therefore, data on the effects of this infection on maternal outcomes are limited, with no clear evidence that pregnant women infected with CHIKV have more obstetric complications. In a prospective study by Fritel et al., pregnant women with CHIKV infection were more likely to be hospitalized than nonpregnant women (8). Robillard et al. identified the first case of CHIKV vertical transmission (9), changing the perspective on perinatal infection. When maternal infection occurs at the end of pregnancy, serious, even life-threatening fetal and neonatal complications, such as meningoencephalitis and disseminated intravascular coagulation, can occur $(8,10-14)$.

Information on the clinical presentation of chikungunya in pregnant women in Latin America is limited $(15-20)$. The case descriptions in this report provide valuable information for the future management of suspected CHIKV infections during pregnancy, including information on the timing of delivery and appropriate level of care, which can help improve neonatal outcomes. The objective of this study was to describe the clinical features of the acute and chronic phases of CHIKV infection in pregnant women who were hospitalized in Fundación Valle del Lili, a fourth-level hospital. This hospital takes care of 1,400 births per year and serves as a reference facility for obstetrics cases of high clinical complexity for the southwest region of Colombia.

\section{Materials and Methods}

\section{Type of Study}

This investigation was a descriptive observational study of a series of cases. Pregnant women of any age who were hospitalized in the Unit of Obstetric High Complexity (UOHC) with CHIKV infection confirmed by reverse transcription PCR (RT-PCR) during January 1-December 31, 2015, were eligible for inclusion. All pregnant patients with RT-PCR-confirmed infections were admitted to the UOHC, regardless of their clinical condition, so they could be better observed to rule out or manage possible adverse outcomes. We conducted a retrospective review of patient medical records to collect information on demographics, medical history, clinical findings, and laboratory results, as well as to review information recorded by the epidemiologic surveillance committee. This project was approved by the Biomedical Research Ethics Committee of the Fundación Clínica Valle de Lili according to ethics act number 25 of December 7, 2015.

\section{Laboratory Testing}

To confirm the diagnosis of CHIKV infection, we performed RT-PCR in real time using the commercial LightMix kit Chikungunya-virus Light Cycler (TIB MOLBIOL, Adelphia, NJ, USA). We performed all CHIKV RT-PCR tests in the clinical laboratory of the Fundación Valle del Lili. Specific CHIKV genotypes were not identified in this study. However, Laiton-Donato et al. identified the genotypes responsible for the CHIKV epidemic in Colombia during 2014-2015 and found only the Asian genotype (21). We ruled out dengue virus infection by measuring blood for specific antibodies and nonstructural protein 1 antigen with the commercial SD BIOLINE Dengue Duo kit (Standard Diagnostic, Inc., Yongin, South Korea).

\section{Case Definitions}

We stratified CHIKV infection into 2 phases: acute (first 10 days of disease) and chronic (after day 10 of disease) (22). We used the definition from the International Sepsis Definitions Conference in 2001 to standardize all cases of sepsis, severe sepsis, and septic shock (23). To assess severe acute maternal morbidity (SAMM) in pregnant women requiring intensive care, we decided to use the World Health Organization's established criteria $(24,25)$. To assess the chronic phase of disease, we contacted all patients by telephone 1 year after acute viremia. We used a survey used in previous studies $(16,26)$ that included questions regarding the criteria for classification of rheumatoid arthritis of the American College of Rheumatology and European League of Rheumatism 2010 (27). The survey included questions on joint pain duration, morning stiffness, joint swelling, muscle pain, and joint redness. Qualified study authors (S.L.O. and J.S.B.) conducted the survey by telephone call (online Technical Appendix Table, https://wwwnc.cdc. gov/EID/article/23/11/17-0480-Techapp1.pdf). 


\section{Data Collection}

We reviewed electronic medical records to obtain information about pregnant women with CHIKV infection and newborns whose births were cared for at the Fundación Valle del Lili. We retrieved the following data: demographics, symptoms and duration of symptoms before hospitalization, findings from physical examination, findings from laboratory tests, and progress during hospitalization. We entered all information collected into an electronic database.

\section{Data Analysis}

We performed a univariate analysis in which the distribution of numerical variables was evaluated by the ShapiroWilk test. We summarized data by using averages and SDs or medians and interquartile ranges (IQRs), as appropriate. We expressed qualitative variables as proportions and performed statistical analysis with the Stata program (StataCorp LLC, College Station, TX, USA).

\section{Results}

We identified 60 patients with confirmed CHIKV diagnoses; all of these patients were hospitalized January-September 2015. No patients hospitalized during October-December 2015 were confirmed to have CHIKV infection. All 60 patients with confirmed CHIKV diagnoses were hospitalized at the OHCU to rule out sepsis and other viral infections, such as dengue. Mean patient age was $26.4 \pm 5.6$ years. Five $(8.3 \%)$ women were in their first trimester ( $<12$ weeks), 17 $(28.3 \%)$ were in their second trimester (12-28 weeks), and $38(63.3 \%)$ were in their third trimester ( $>28$ weeks). Fifteen $(25 \%)$ women pregnant in their third trimester completed pregnancy during the hospitalization, and 9 (15\%) women required treatment in the intensive care unit (ICU).

\section{Clinical Findings}

The most frequent clinical findings at the time of consultation at the emergency department were arthralgia (55/60, $91.6 \%)$, followed by fever $(21 / 60,35 \%)$ (Table 1$)$. Other reported clinical manifestations were headache, rash, and myalgia. The interval between the onset of CHIKV symptoms and admission to the $\mathrm{OHCU}$ was $1.4 \pm 0.5$ days for patients in their first trimester, $1.4 \pm 0.9$ days for patients in their second, and $2.4 \pm 1.9$ days for patients in their third. We observed hemorrhagic manifestations among women in their third trimester (Table 1). Laboratory results showed leukopenia $(<4,000$ cells $/ \mu \mathrm{L})$ in $35(58.3 \%)$ women and thrombocytopenia $(<150,000 / \mu \mathrm{L})$ and elevated transaminase levels $(>32 \mu \mathrm{L})$ in $10(16.7 \%)$ women. Thirty-one $(51.7 \%)$ women had electrolyte abnormalities: 24 (77.4\%) hyperchloremia $(>107 \mathrm{mmol} / \mathrm{L}), 2(6.5 \%)$ hyponatremia $(<135 \mathrm{mmol} / \mathrm{L})$, and $5(16.1 \%)$ hypokalemia $(<3.5 \mathrm{mmol} / \mathrm{L})$. The median viral load for CHIKV was $1.76 \times 10^{5}$ (IQR $1.17 \times 10^{4}$ to 2.95 $\times 10^{6}$ ) copies $/ \mathrm{mL}$. For all patients, test results for dengue viruses (nonstructural protein 1, IgM, and IgG) were negative.

We stratified the observed obstetric complications by the trimester in which the acute CHIKV infection occurred. Among women in their first trimester, 1 had a spontaneous abortion; among women in their second trimester, 3 had preeclampsia and 1 was admitted to the ICU because of CHIKV sepsis; and among women in their third trimester, 8 had CHIKV sepsis. The average hospital stay was longer for the women with CHIKV sepsis in their third trimester ( $4.3 \pm 2.7$ days) than for pregnant women without CHIKV (2.4 \pm 1.2 days). The obstetric pathologies observed during the third trimester were premature rupture of membranes $(3 / 38,7.9 \%)$, intrauterine growth restriction $(2 / 38,5.3 \%)$, preeclampsia $(6 / 38,15.8 \%)$, preterm delivery $(1 / 38,2.6 \%)$, and postdelivery hemorrhage $(3 / 38,7.9 \%)$.

\begin{tabular}{|c|c|c|c|c|}
\hline & & \multicolumn{3}{|c|}{ Trimester } \\
\hline & & First, $n=5$ & Second, $\mathrm{n}=17$ & Third, $\mathrm{n}=38$ \\
\hline Patient age, $\mathrm{y}$, average $\pm \mathrm{SD}$ & $26.4 \pm 5.6$ & $27.8 \pm 7.5$ & $26.8 \pm 5.8$ & $26 \pm 5.3$ \\
\hline Gestational age of fetus, wks, average \pm SD & $28.5 \pm 8.8$ & $13 \pm 5.8$ & $20.6 \pm 5.6$ & $34 \pm 3.7$ \\
\hline \multicolumn{5}{|l|}{ Reason for consultation, no. (\%) } \\
\hline Arthralgia & $55(91.7)$ & $5(100)$ & $17(100)$ & $33(86.8)$ \\
\hline Fever & $21(35)$ & $0(0)$ & $5(29.4)$ & $16(42.1)$ \\
\hline Pruritus & $4(6.7)$ & $0(0)$ & $0(0)$ & $4(10.5)$ \\
\hline Headaches & $9(15)$ & $1(20)$ & $4(23.5)$ & $4(10.5)$ \\
\hline Rash & $9(15)$ & $4(80)$ & $5(29.4)$ & $0(0)$ \\
\hline \multicolumn{5}{|c|}{ Signs and symptoms during hospitalization, no. (\%) } \\
\hline Fever & $11(18.3)$ & $0(0)$ & $0(0)$ & $11(28.9)$ \\
\hline Polyarthralgia & $56(93.3)$ & $5(100)$ & $16(94.1)$ & $35(92.1)$ \\
\hline Headaches & $45(75)$ & $4(80)$ & $12(70.6)$ & $29(76.3)$ \\
\hline Rash & $52(86.7)$ & $5(100)$ & $13(76.5)$ & $34(89.5)$ \\
\hline Myalgia & $46(76.7)$ & $4(80)$ & $13(76.5)$ & $29(76.3)$ \\
\hline Low back pain & $28(46.7)$ & $3(60)$ & $6(35.3)$ & $19(50)$ \\
\hline Emesis & $3(5)$ & $0(0)$ & $1(5.9)$ & $2(5.3)$ \\
\hline Nausea & $11(18.3)$ & $2(40)$ & $2(11.8)$ & $7(18.4)$ \\
\hline Epistaxis & $2(3.3)$ & $0(0)$ & $0(0)$ & $2(5.3)$ \\
\hline Gingivorragia & $3(5)$ & $0(0)$ & $0(0)$ & $3(7.9)$ \\
\hline
\end{tabular}




\section{Intrapartum Period}

Fifteen $(39.5 \%)$ of the 38 patients who sought treatment for chikungunya fever in the third trimester gave birth during the hospitalization: 10 by vaginal delivery and 5 by cesarean section (because of unsatisfactory fetal orientation in the womb). The mean gestational age of their newborns at birth was $38.5 \pm 1.08$ weeks. For these 15 women, the average number of days from onset of symptoms to labor was $6.3 \pm 1.9$ days. Vital signs were monitored every 2 hours and platelets and hemoglobin every 24 hours, and no severe thrombocytopenia or anemia occurred. These patients required resuscitation with intravenous crystalloid fluids, with a cumulative fluid balance of $328 \pm 657 \mathrm{~mL}$ during the obstetric event. Three (20\%) women with regular uterine activity had fevers, so the doctors performed tocolysis with nifedipine for $2.3 \pm 0.94$ days to delay labor and prevent birth during the period of intrapartum fever.

\section{Intensive Care Unit}

Nine (15\%) patients required ICU admission, 8 (89\%) of which were in their last trimester of pregnancy. Although women in the third trimester comprised $63.3 \%$ of the study population, they comprised almost all of the ICU admissions. Seven (78\%) of the 9 ICU patients did not have other comorbidities, and $2(22 \%)$ had reported previous cardiac arrhythmias. All 9 women had sepsis, $7(78 \%)$ had the criteria for severe sepsis, and none had septic shock. Bacteria cultures were performed with these patients' blood samples, and all were negative, ruling out nosocomial bacterial infection. Complications developed in some patients, with postdelivery hemorrhage occurring most frequently (11.1\%). At admission to the ICU, lactic acid and base deficit were measured. Of the 9 patients sent to the ICU, mean lactic acid level was $2.6 \pm 2.39 \mathrm{mmol} / \mathrm{L}$ and base deficit was $-5 \pm 1.4 \mathrm{mmol} / \mathrm{L} ; 6$ (66.7\%) patients had hyperlactatemia.

Upon admission to the ICU, all 9 patients received resuscitation with crystalloids $(30 \mathrm{~mL} / \mathrm{kg}$ in $500 \mathrm{~mL}$ boluses every 15-30 min), resulting in a fluid balance of $960.3 \mathrm{~mL}$ at the end of resuscitation. Three women had hypertension, and 6 had clinical signs of tissue hypoperfusion. The mean APACHE II (Acute Physiology and Chronic Health Evaluation II) score was $10.44 \pm 4.71$ points, and death was the prognosis for $15 \%$ of these patients. All patients had SAMM criteria (Table 2); the main dysfunctions found were renal $(33 \%)$, vascular $(22 \%)$, and hepatic $(22 \%)$. Although the patients had SAMM criteria, no maternal deaths were reported.

\section{Newborn Infants}

Of the 15 infants born during their mothers' acute CHIKV infection, 12 were hospitalized as recommended by the pediatric neonatologist to observe their clinical progress
Table 2. Criteria for severe acute maternal morbidity among 9 pregnant women with chikungunya virus infection who were admitted to intensive care, Colombia, 2015*

\begin{tabular}{lc}
\hline Criteria & No. (\%) patients \\
\hline Organ dysfunction† & $7(77.8)$ \\
Hepatic & $2(22.2)$ \\
Renal & $3(33.3)$ \\
Vascular & $2(22.2)$ \\
\hline Clinical diagnosis & $9(100)$ \\
Severe preeclampsia & $3(33.3)$ \\
Severe postpartum hemorrhage & $1(11.1)$ \\
Sepsis & $9(100)$ \\
\hline Interventions in critical care & $9(100)$ \\
Admission to intensive care unit & $9(100)$ \\
Transfusions of $>3$ units of red blood cells & $2(22.2)$ \\
\hline *The World Health Organization's definition for severe acute maternal \\
morbidity was used (24,25). \\
tHepatic dysfunction was defined as hyperbilirubinemia (bilirubin $>100$ \\
$\mu$ mol/L or 6 mg/dL). Renal dysfunction was defined as oliguria <400 mL \\
that did not resolve after administration of fluids or diuretics. Vascular \\
dysfunction was defined as hypovolemia requiring transfusion or use of \\
vasoactives.
\end{tabular}

and to rule out vertical transmission. The average duration of hospitalization of newborns was 4 days. Because this event was the department of obstetrics and neonatology's first experience managing an outbreak of CHIKV in pregnant women, the hospital did not have a protocol to care for newborns born from mothers with CHIKV infections. A decision was made to perform RT-PCR only with newborns of mothers having viremia near the time of delivery ( $50 \%$ of the 12 hospitalized newborns), and all were negative for the CHIKV genome. At physical examination, 5 neonates had no abnormalities, and 1 neonate had a short neck with no internal anatomic abnormalities or problems with mobility. For this neonate, a karyotype was performed, leading to the diagnosis of Turner syndrome. Regarding the laboratory results of the other neonates, $2(16.7 \%)$ of 12 had leukocytosis and $1(8.3 \%)$ of 12 had lymphocytosis. No abnormalities were found with renal, liver, or platelet function tests. No neurologic or cardiovascular abnormalities were observed.

\section{Postdelivery Follow-up}

One year after delivery, we called study participants to perform follow-up of the chronic phase of disease. Only 36 patients $(60 \%)$ could be contacted; the other 24 patients did not or were not willing to answer our calls. Twenty-three women had no residual symptoms. However, 13 patients (36\% of the women who responded to the survey) experienced arthralgia in $\geq 2$ joints. Of these women, 8 had joint swelling, 7 had erythema, and 4 had myalgia. Nine had an inflammatory pattern that included morning stiffness. The presence of these symptoms indicates these women were experiencing a relapse of acute disease. Joint pain reoccurred $72.6 \pm 74.15$ days after acute CHIKV infection and persisted for $186.9 \pm 85.78$ days. Five women required follow-up with a rheumatology specialist. 


\section{Discussion}

Our cohort included 60 pregnant women with a diagnosis of CHIKV confirmed by RT-PCR. To enable observation of the behavior of the disease and the obstetric outcomes, all patients with confirmed CHIKV infection were hospitalized, regardless of clinical stability and severity of the infection. In 2015, the Fundación Clínica Valle del Lili did not have an established protocol for the management of pregnant women with CHIKV infection. The most common signs of illness in the patients admitted to the UOHC were polyarthralgia, exanthema, myalgia, headache, and fever. Thiberville et al. conducted a prospective study during the epidemic on Reunión Island that included 54 adults with CHIKV infection (28). This study indicated the same signs described in our series. Our analysis also confirms that the clinical manifestations do not vary between nonpregnant adults and pregnant women (29).

Previous studies of the nonpregnant population indicated that CHIKV can cause illnesses and deaths associated with sepsis (30-32). Our study reports 9 pregnant women with CHIKV-induced sepsis, and all required ICU treatment. Seven (77.8\%) of those women had severe sepsis. Target-guided resuscitation was performed with crystalloids and vasopressors under strict surveillance of water overload. Among patients with SAMM, the APACHE II score was $10.4 \pm 4.7$ points, and $15 \%$ had a prognosis of death; however, no deaths occurred. These findings suggest that CHIKV infection during pregnancy can cause severe sepsis with organ dysfunction and tissue hypoperfusion.

CHIKV infection appears to have clinical presentations that differ by trimester of pregnancy. Another report related maternal infection with vertical transmission and pregnancy loss (33), although these occurrences were uncommon. In our cohort, spontaneous abortion occurred once; however, two thirds of our patients $(38 / 60)$ were in their third trimester. This high concentration of women in late pregnancy might be explained by the common practice of low-complexity obstetrics centers of Colombia referring high-complexity obstetrics candidates (pregnant women at term or during labor with acute febrile syndrome) to Fundación Valle del Lili's UOHC.

Chikungunya is a potential risk for neonates born to symptomatic women $(11,14)$. The most common clinical signs in newborns were fever, irritability, rash, hyperalgesia syndrome, diffuse limb edema, meningoencephalitis, and bullous dermatitis $(8,11)$. With the Réunion Island outbreak of 2005, Gérardin et al. found that the risk for vertical transmission increased to $50 \%$ when maternal viremia was present during delivery (11). Furthermore, Ramful et al. found that the risk for mother-to-child transmission increased when the acute infection was documented during the intrapartum period (12). These findings suggest that the intrapartum period is the most critical time for vertical transmission. In 2016, a multicenter study occurring in 3 Latin America countries (El Salvador, Colombia, and Dominican Republic) showed vertical transmission rates ranging from $27.7 \%$ to $48.3 \%(20)$.

In our cohort, we could not rule out the transmission of CHIKV infection in all newborns but report that none had clinical signs of congenital infection. We could test only $50 \%$ of the newborns with RT-PCR, and all were negative. We delayed labor to prevent birth during the early febrile phase. The average interval from the onset of maternal symptoms to delivery of $6.3 \pm 1.4$ days might have been enough time for the passive transfer of antibodies to occur to prevent symptomatic infection in the newborn. We strictly monitored these patients for the presence of fever, thrombocytopenia, or intrapartum hemodynamic decompensation; $20 \%$ of the patients with intrapartum fever required tocolysis to delay labor. We have used this approach to prevent dengue maternal complications and to reduce dengue vertical transmission at Fundación Valle del Lili. Our findings suggest delaying the birth as long as possible in patients with acute febrile CHIKV infections is necessary, as long as there are no obstetric contraindications. In favor of this perspective, in the Leglet et al. study, 118 of 151 pregnant women with CHIKV infection had a clearance of their viremia before completing gestation, and no cases of vertical transmission were reported (34).

We found that the median viral load for CHIKV was $1.76 \times 10^{5}\left(\mathrm{IQR} 1.17 \times 10^{4}\right.$ to $\left.2.95 \times 10^{6}\right)$ copies $/ \mathrm{mL}$. In 2006, Panning et al. conducted a study with patients who returned to Europe from the Indian Ocean with a diagnosis of CHIKV and reported a mean viral load of $9.85 \times 10^{7}$ copies/mL (35).

Although this type of study cannot establish causality, we found a high incidence of preeclampsia $(15.7 \%)$ in patients with CHIKV. In Colombia, preeclampsia is the leading cause of maternal illness and death; in 2014, a total of 10,499 cases of maternal illnesses were reported, with hypertensive disorders being the main associated cause (60.5\% of cases) (36). Likewise, hypertensive disorders are one of the main reasons for consultations with the Fundación Valle del Lili ( $24 \%$ of all consultations per year).

The chronic phase of CHIKV has been poorly described in the obstetric population. In our study, 36 women $(60 \%)$ were followed up 1 year after seeking treatment for acute CHIKV infection, and 13 patients $(36 \%)$ were found to have episodes of arthralgia in $\geq 2$ joints (relapsed infections). These findings are consistent with the study by Rodriguez et al., which characterized the chronic phase of CHIKV in an adult population in Colombia and reported that $50 \%$ of patients had chronic rheumatologic disorders with an inflammatory pattern (16). This observation is consistent with that from our report, in which 5 patients $(13.9 \%)$ required care by a rheumatology service. Similarly, Rodríguez et al. 
reported that a higher proportion of chronic pain might occur with some groups, such as women and the elderly (16). These findings emphasize the need to further characterize the degree of disability caused by rheumatologic symptoms in this population.

Our findings have methodologic limitations. First, this study involved a small retrospective cohort without a control population, so assessing causality and risk factors was not possible. Second, the hospital used was a reference center for the most serious cases in the region, generating a selection bias in recruited patients and explaining the high incidence of preeclampsia in this series. Third, electronic medical records of hospitalized women were used, which led to a restricted nongeneralizable sample. Fourth, because follow-up of the chronic phase of the disease was 1 year after onset of symptoms, memory bias could have affected our results. Finally, vertical transmission could have been underestimated given that not all neonates were hospitalized and, of those hospitalized, only half had RT-PCR to evaluate for CHIKV infection.

In conclusion, chikungunya is an emerging disease in the Western Hemisphere. All personnel in charge of obstetric populations should be aware of the behavior of CHIKV infection during pregnancy. This study suggests that CHIKV might cause cases of sepsis with hypoperfusion and organ dysfunction. Although the number of neonates potentially exposed was low, good perinatal outcomes without vertical transmission of infection justifies high-complexity obstetric center care of pregnant women, particularly those with signs and symptoms of CHIKV infection near term or at the time of delivery. Finally, the presence of residual pain in our patients suggests the need for follow-up throughout the first year after infection.

\section{Acknowledgments}

The authors thank Angelica Forero Ladino and José Casallas for writing assistance.

Dr. Escobar is director of the High-Complexity Obstetrics Care Unit and director of the Department of Gynecology and Obstetrics at the Fundación Valle del Lili in Cali, Colombia. Her research interests are viral infections during pregnancy and critical care in obstetrics.

\section{References}

1. Dalrymple JPC. Alphaviruses. In: Fields virology. Knipe DM, editor. New York: Raven Press; 1990. p. 713-61.

2. Hamer DH, Chen LH. Chikungunya: establishing a new home in the Western Hemisphere. Ann Intern Med. 2014;161:827-8. http://dx.doi.org/10.7326/M14-1958

3. Yactayo S, Staples JE, Millot V, Cibrelus L, Ramon-Pardo P. Epidemiology of chikungunya in the Americas. J Infect Dis. 2016;214(suppl 5):S441-5. http://dx.doi.org/10.1093/infdis/jiw390

4. Instituto Nacional de Salud - Dirección de Vigilancia y Análisis del Riesgo en Salud Pública. Boletin epidemiológico semanal. 2016 [cited 2017 Jun 22]. http://www.ins.gov.co/boletin-epidemiologico/ Boletn $\% 20$ Epidemiolgico/2016\%20Bolet $\%$ C3\%ADn $\% 20$ epidemiol\%C3\%B3gico\%20semana\%2051.pdf

5. Bodenmann P, Genton B. Chikungunya: an epidemic in real time. Lancet. 2006;368:258. http://dx.doi.org/10.1016/ S0140-6736(06)69046-6

6. Pialoux G, Gaüzère B-A, Jauréguiberry S, Strobel M. Chikungunya, an epidemic arbovirosis. Lancet Infect Dis. 2007;7:319-27. http://dx.doi.org/10.1016/S1473-3099 (07)70107-X

7. Brighton SW, Prozesky OW, de la Harpe AL. Chikungunya virus infection. A retrospective study of 107 cases. S Afr Med J. 1983;63:313-5.

8. Fritel X, Rollot $\mathrm{O}$, Gérardin $\mathrm{P}$, Gaūzère BA, Bideault J, Lagarde L, et al.; Chikungunya-Mere-Enfant Team. Chikungunya virus infection during pregnancy, Réunion, France, 2006. Emerg Infect Dis. 2010;16:418-25. http://dx.doi.org/10.3201/eid1604.091403

9. Robillard P-Y, Boumahni B, Gérardin P, Michault A, Fourmaintraux A, Schuffenecker I, et al. Vertical maternal fetal transmission of the chikungunya virus. Ten cases among 84 pregnant women [in French]. Presse Med. 2006;35:785-8. http://dx.doi.org/10.1016/S0755-4982(06)74690-5

10. Gérardin P, Barau G, Michault A, Bintner M, Randrianaivo H, Choker G, et al. Multidisciplinary prospective study of mother-tochild chikungunya virus infections on the Island of La Réunion. PLoS Med. 2008;5:e60. http://dx.doi.org/10.1371/ journal.pmed.0050060

11. Gérardin P, Couderc T, Bintner M, Tournebize P, Renouil M, Lémant J, et al.; Encephalchik Study Group. Chikungunya virusassociated encephalitis: a cohort study on La Réunion Island, 2005-2009. Neurology. 2016;86:94-102. http://dx.doi.org/10.1212/ WNL.0000000000002234

12. Ramful D, Carbonnier M, Pasquet M, Bouhmani B, Ghazouani J, Noormahomed T, et al. Mother-to-child transmission of chikungunya virus infection. Pediatr Infect Dis J. 2007;26:811-5. http://dx.doi.org/10.1097/INF.0b013e3180616d4f

13. Senanayake MP, Senanayake SM, Vidanage KK, Gunasena S, Lamabadusuriya SP. Vertical transmission in chikungunya infection. Ceylon Med J. 2009;54:47-50. http://dx.doi.org/10.4038/ cmj.v54i2.865

14. Villamil-Gómez W, Alba-Silvera L, Menco-Ramos A, Gonzalez-Vergara A, Molinares-Palacios T, Barrios-Corrales M, et al. Congenital chikungunya virus infection in Sincelejo, Colombia: a case series. J Trop Pediatr. 2015;61:386-92. http://dx.doi.org/10.1093/tropej/fmv051

15. Castañeda-Orjuela C, Díaz-Jiménez D, Rodríguez-Castillo L, Paternina-Caicedo A, Pinzón-Redondo H, Alvis-Guzman N, et al. PHS44 - medical care costs of chikungunya virus infection in a pediatric population in Colombia. Value Health. 2015;18:A254-5. http://dx.doi.org/10.1016/j.jval.2015.03.1483

16. Rodriguez-Morales AJ, Gil-Restrepo AF, Ramírez-Jaramillo V, Montoya-Arias CP, Acevedo-Mendoza WF, Bedoya-Arias JE, et al. Post-chikungunya chronic inflammatory rheumatism: results from a retrospective follow-up study of 283 adult and child cases in La Virginia, Risaralda, Colombia. F1000 Res. 2016;5:360. http://dx.doi.org/10.12688/f1000research.8235.1

17. Rodríguez-Nieves M, García-García I, García-Fragoso L. Perinatally acquired chikungunya infection: the Puerto Rico experience. Pediatr Infect Dis J. 2016;35:1163. http://dx.doi.org/ 10.1097/INF.0000000000001261

18. Alvarado-Socarras JL, Ocampo-González M, Vargas-Soler JA, Rodriguez-Morales AJ, Franco-Paredes C. Congenital and neonatal chikungunya in Colombia. J Pediatric Infect Dis Soc. 2016;5:e1720. http://dx.doi.org/10.1093/jpids/piw021

19. Lyra PPR, Campos GS, Bandeira ID, Sardi SI, Costa LFM, Santos FR, et al. Congenital chikungunya virus infection after an 
outbreak in Salvador, Bahia, Brazil. AJP Rep. 2016;6:e299-300. http://dx.doi.org/10.1055/s-0036-1587323

20. Torres JR, Falleiros-Arlant LH, Dueñas L, Pleitez-Navarrete J, Salgado DM, Castillo JB-D. Congenital and perinatal complications of chikungunya fever: a Latin American experience. Int J Infect Dis. 2016;51:85-8. http://dx.doi.org/ 10.1016/j.ijid.2016.09.009

21. Laiton-Donato K, Usme-Ciro JA, Rico A, Pardo L, Martínez C, Salas D, et al. Phylogenetic analysis of chikungunya virus in Colombia: evidence of purifying selection in the E1 gene [in Spanish]. Biomedica. 2015;36:25-34. http://dx.doi.org/10.7705/ biomedica.v36i0.2990

22. Kucharz EJ, Cebula-Byrska I. Chikungunya fever. Eur J Intern Med. 2012;23:325-9. http://dx.doi.org/10.1016/j.ejim.2012.01.009

23. Levy MM, Fink MP, Marshall JC, Abraham E, Angus D, Cook D, et al.; Society of Critical Care Medicine; The European Society of Intensive Care Medicine; American College of Chest Physicians; American Thoracic Society; Surgical Infection Society. $2001 \mathrm{SCCM} / \mathrm{ESICM} / \mathrm{ACCP} / \mathrm{ATS} / \mathrm{SIS}$ International Sepsis Definitions Conference. Crit Care Med. 2003;31:1250-6. http://dx.doi.org/10.1097/01.CCM.0000050454.01978.3B

24. Mantel GD, Buchmann E, Rees H, Pattinson RC. Severe acute maternal morbidity: a pilot study of a definition for a near-miss. Br J Obstet Gynaecol. 1998;105:985-90. http://dx.doi.org/ 10.1111/j.1471-0528.1998.tb10262.x

25. Say L, Pattinson RC, Gülmezoglu AM. WHO systematic review of maternal morbidity and mortality: the prevalence of severe acute maternal morbidity (near miss). Reprod Health. 2004;1:3. http://dx.doi.org/10.1186/1742-4755-1-3

26. Rodríguez-Morales AJ, Calvache-Benavides CE, Giraldo-Gómez J, Hurtado-Hurtado N, Yepes-Echeverri MC, García-Loaiza CJ, et al. Post-chikungunya chronic arthralgia: results from a retrospective follow-up study of 131 cases in Tolima, Colombia. Travel Med Infect Dis. 2016;14:58-9. http://dx.doi.org/10.1016/ j.tmaid.2015.09.001

27. Aletaha D, Neogi T, Silman AJ, Funovits J, Felson DT, Bingham CO III, et al. 2010 Rheumatoid arthritis classification criteria: an American College of Rheumatology/European League Against Rheumatism collaborative initiative. Arthritis Rheum. 2010;62:2569-81. http://dx.doi.org/10.1002/art.27584

28 Thiberville S-D, Boisson V, Gaudart J, Simon F, Flahault A, de Lamballerie X. Chikungunya fever: a clinical and virological investigation of outpatients on Reunion Island, south-west Indian Ocean. PLoS Negl Trop Dis. 2013;7:e2004. http://dx.doi.org/10.1371/journal.pntd.0002004

29. Economopoulou A, Dominguez M, Helynck B, Sissoko D, Wichmann O, Quenel P, et al. Atypical chikungunya virus infections: clinical manifestations, mortality and risk factors for severe disease during the 2005-2006 outbreak on Réunion. Epidemiol Infect. 2009;137:534-41. http://dx.doi.org/10.1017/ S0950268808001167

30. Charrel RN, de Lamballerie X. Chikungunya virus in north-eastern Italy: a consequence of seasonal synchronicity. Euro Surveill. 2008;13:8003.

31. Borgherini G, Poubeau P, Staikowsky F, Lory M, Le Moullec N, Becquart JP, et al. Outbreak of chikungunya on Reunion Island: early clinical and laboratory features in 157 adult patients. Clin Infect Dis. 2007;44:1401-7. http://dx.doi.org/10.1086/517537

32. Rollé A, Schepers K, Cassadou S, Curlier E, Madeux B, Hermann-Storck C, et al. Severe sepsis and septic shock associated with chikungunya virus infection, Guadeloupe, 2014. Emerg Infect Dis. 2016;22:891-4. http://dx.doi.org/10.3201/eid2205.151449

33. Touret Y, Randrianaivo H, Michault A, Schuffenecker I, Kauffmann E, Lenglet Y, et al. Early maternal-fetal transmission of the chikungunya virus [in French]. Presse Med. 2006;35:1656-8. http://dx.doi.org/10.1016/S0755-4982(06)74874-6

34. Lenglet Y, Barau G, Robillard P-Y, Randrianaivo H, Michault A, Bouveret A, et al. Chikungunya infection in pregnancy: evidence for intrauterine infection in pregnant women and vertical transmission in the parturient. Survey of the Reunion Island outbreak [in French]. J Gynecol Obstet Biol Reprod (Paris). 2006;35:578-83. http://dx.doi.org/10.1016/S0368-2315(06)76447-X

35. Panning M, Grywna K, van Esbroeck M, Emmerich P, Drosten C. Chikungunya fever in travelers returning to Europe from the Indian Ocean region, 2006. Emerg Infect Dis. 2008;14:416-22. http://dx.doi.org/10.3201/eid1403.070906

36. Instituto Nacional de Salud. Protocolo de Vigilancia en Salud Pública. Morbilidad materna extrema. 2016 Mar 29 [cited 2017 Jul 4]. http://www.ins.gov.co/lineas-de-accion/SubdireccionVigilancia/sivigila/Protocolos\%20SIVIGILA/PRO $\% 20$ Morbilidad\%20Materna\%20Extrema.pdf

Address for correspondence: María Escobar, Fundación Clínica Valle del Lili, Carrera 98 No. 18-49, Cali 760032, Colombia; email: mayaev@hotmail.com

\section{PubMed}

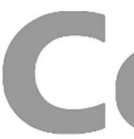
cent tra

\section{PublMed}

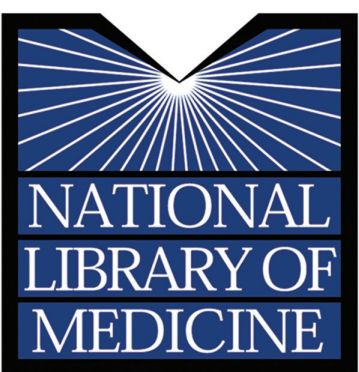

\section{Find Emerging Infectious Diseases content in the digital archives of the National Library of Medicine} www.pubmedcentral.nih.gov 